\title{
Affirming Pride
}

\author{
Cynthia M.A. Geppert, MD
}

Hope will never be silent.

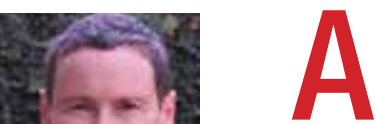

mid the parades and speeches that commemorate Pride Month across the United States, a remarkable event occurred in Florida at the Orlando Veterans Affairs Healthcare System. At the 11th annual celebration of Pride on June 21, US Department of Veterans Affairs (VA) Secretary Denis R. McDonough made a historic announcement, "We are taking the first necessary steps to expand VA's care to include gender-confirmation surgery, thus allowing transgender vets to go through the full gender-confirmation process with VA by their side." 2

The proclamation reflected the results of a review of VA transgender policies that McDonough had ordered in February 2021 to coordinate VA policies with those of the US Department of Defense (DoD) and to actualize President Biden's January 2021 executive order that prohibited discrimination on the basis of sexual orientation or gender identity. ${ }^{3,4}$ In an interview with NPR shortly after the Orlando commemoration, Secretary McDonough reported that the governing body overseeing VA health care services unanimously endorsed the proposal. ${ }^{5}$ The National Center for Transgender Equity estimates there are 134,000 transgender veterans. ${ }^{6}$ VA authorities believe 4000 transgender veterans may be interested in obtaining the new gender-affirming benefit when it is available, and Secretary McDonough indicated that about 543 veterans a year soon might be eligible.,

Transgender veterans and their supporters along with many of the VA practitioners who care for them had long waited and hoped for this announcement. The Secretary ended a toolong period in which transgender veterans encountered enormous practical, financial, and personal obstacles, causing frustration and despair on their journey to becoming who they knew they are. Although VA previously did not provide gender-affirmation surgery, it did deliver other forms of transgender care to veterans, such as hormone therapy and other transition- related services. Yet it was painful for transgender veterans and their health care professionals (HCPs) to see that under the VA medical benefits package prior to Secretary McDonough's historic announcement, gender-affirmation surgery was not deemed care "to promote, preserve, or restore the health of the individual."

Similarly, the decision is the beginning of the end of an ethical dilemma with which many VA clinicians struggled: They had the competence to perform gender-affirming surgery, but VA policy prohibited them from providing it to their patients. ${ }^{9,10}$ The 2013 directive issued under the Obama administration made the ethics of gender-confirmation surgery even more complex. A VA surgeon could perform "medically-indicated procedures" or treat "other medical conditions" even if it simultaneously furthered gender transition. What the surgeon could not perform was a procedure solely for the purpose of gender transition. Because transgender veterans seeking gender-affirmation surgery were forced to go outside the VA system and use their resources to pay for the surgery, VA did permit practitioners to perform preoperative and postoperative treatment, including treating surgical complications of an outside gender-affirmation surgery. VA HCPs were placed in a catch-22 situation that pitted their duty to care in accordance with the preferences and interests of the veteran against their obligation to practice and adhere to VA policy and federal regulation. ${ }^{8}$ With his Pride-month speech, Secretary McDonough resolved this conflict for VA HCPs and made a strong public declaration VA should and will provide genderaffirming surgery that can promote, preserve, and restore the health of transgender veterans.

Secretary McDonough called the move to formally change the rule regarding gender-affirming surgery "the right thing to do" and emphasized that it was "life-saving." This last remark was in recognition of the strong evidence demonstrating the adverse psychological impact on transgender veterans of the previous position. ${ }^{2}$ 
Denial of gender-confirmation surgery was not the only health care inequity identified among transgender veterans. Research inside and outside VA has found significant health disparities between transgender and nontransgender veterans, including higher rates of depression, suicidality, serious mental illness, posttraumatic stress disorder, military sexual trauma, and homelessness. ${ }^{11}$ The provision of gender-affirming surgery to transgender veterans whether through VA hospitals or through partnerships with academic affiliates and the community is a major step to remedy these disparities. A 2019 systematic review found that gender-affirming surgery is far from cosmetic: It leads to marked improvement in many of the mental health problems transgender persons experience. ${ }^{12}$

Anyone who has experienced the snail's pace of change in the behemoth VA bureaucracy knows that this initial movement is only the beginning of the laborious federal process of changing the regulation that currently prohibits VA from offering and paying for genderconfirmation surgery under the VA medical benefits package. Once the regulation is changed, then VA will be empowered to establish policy that in Secretary McDonough's words, "will ensure the equitable treatment and safety of transgender veterans." ${ }^{2}$ The decision to eventually provide gender-confirmation surgery as part of VA care was an important aspect of the agency's overall attempt to make VA more welcome to lesbian, gay, bisexual, transgender, and queer (LGBTQ) veterans. During the Orlando speech, Secretary McDonough also announced that VA was changing the name of its LGBT program to LGBTQ+ to clearly communicate that all veterans are included in VA care. ${ }^{2}$

The announcement sends a powerful message of hope, which was a central theme of slain San Francisco supervisor, Harvey Milk, an early and influential LGBTQ activist and advocate. ${ }^{1}$ But as always in our polarized country, there was immediate opposition to the proposal arguing that the surgery would place transgender veterans at greater risk of depression and suicide, was not compatible with the VA mission and diverts VA funding from meeting more le- gitimate care needs in a timely manner. ${ }^{11}$ It is a sad irony that transgender veterans defended the freedom of their opponents to express their opinion and had to fight this long and hard for their liberty to live as they choose.

\section{Disclaimer}

The opinions expressed herein are those of the authors and do not necessarily reflect those of Federal Practitioner, Frontline Medical Communications Inc., the US Government, or any of its agencies.

\section{References}

1. Milk H. An Archive of Hope: Harvey Milk's Speeches and Writings. Beck JE, Morris CE III, eds. University of California; 2013.

2. US Department of Veterans Affairs, Office of Public and Intergovernmental Affairs. Remarks by Secretary Denis R. McDonough. Orlando VA Healthcare System 11th Annual Pride Month Celebration. Orlando Florida. Published June 19, 2021. Accessed July 19, 2021. https://www.va.gov/opa /speeches/2021/06_19_2021.asp

3. US Department of Veterans Affairs. Secretary orders review of VA's transgender policies. Published February 24, 2021. Accessed July 19, 2021. https://blogs.va.gov/VAntage/85152 /secretary-orders-review-vas-transgender-policies

4. US Executive Office of the President, Biden JR. Executive Order 13998: Preventing and combatting discrimination on the basis of gender identity or sexual orientation. Published January 20, 2021. Accessed July 19, 2021. https://www.white house.gov/briefing-room/presidential-actions/2021/01/20 /executive-order-preventing-and-combating-discrimination -on-basis-of-gender-identity-or-sexual-orientation

5. Shapiro A. Veterans Affairs secretary on gender confirmation surgery for transgender veterans. NPR. Published July 8, 2021. Accessed July 19, 2021. https://www.npr .org/2021/07/08/1014339011/veteran-affairs-secretary-on -gender-confirmation-surgery-for-transgender-veteran

6. The National Center for Transgender Equity. Issues: military and veterans. Accessed July 18, 2021. https://transequality .org/issues/military-veterans

7. Shane L III. VA to offer gender surgery to transgender vets for the first time. Military Times. Published June 19, 2021. Accessed July 19, 2021. https://www.militarytimes.com /veterans/2021/06/19/va-to-offer-gender-surgery-to -transgender-vets-for-the-first-time

8. US Department of Veterans Affairs, Veterans Health Administration. VHA Directive 1341(2): Providing health care for transgender and intersex veterans. Published May 23, 2018. Updated June 26, 2020. Accessed July 20, 2021. https://www .va.gov/vhapublications/ViewPublication.asp?pub_ID=6431

9. Kuzon WM Jr, Sluiter E, Gast KM. Exclusion of medically necessary gender-affirming surgery for america's armed services veterans. AMA J Ethics. 2018;20(4):403-413. Published 2018 Apr 1. doi:10.1001/journalofethics.2018.20.4.sect1-1804

10. Brown GR, Jones KT. Mental health and medical health disparities in 5135 transgender veterans receiving healthcare in the Veterans Health Administration: a case-control study. LGBT Health. 2016;3(2):122-131. doi:10.1089/gbt.2015.0058

11. Wernick JA, Busa S, Matouk K, Nicholson J, Janssen A. A systematic review of the psychological benefits of genderaffirming surgery. Urol Clin North Am. 2019;46(4):475-486. doi:10.1016/j.ucl.2019.07.002

12. Brufke J. GOP lawmakers push back on VA's plans to offer gender reassignment surgery. NY Post. June 28, 2021. Accessed July 19, 2021. https://nypost.com/2021/06/28/gop -lawmakers-push-back-on-veterans-affairs-plans-to-offer -gender-reassignment-surgery 